\title{
Performance Enhancement of Membrane Distillaiton Process of Fruit Juice
}

\author{
Deshmukh S.K*, Sapkal V.S and Sapkal RS \\ Sant Gadge Baba Amravati University, Amravati, Maharashtra, India
}

\begin{abstract}
In this work Membrane Distillation is applied to concentrate orange Juice. The orange juice model solution used in this study was prepared with sucrose pro-analysis grade, citral and ethyl butyrate, $98 \%$. The experiments were performed on a flat sheet module using sucrose solution as feeds. The concentration of a sucrose solution, used as a model fruit juice was carried out in a direct contact membrane distillation using hydrophobic PTFE (Polytetrafluoroethylene) membrane of pore size $0.2 \mu \mathrm{m}$ and porosity $70 \%$. Surface modification of PTFE membrane has been carried out by treating membrane with alcohol and water solution to make it hydrophilic and then hydrophobicity was regained by drying. The influences of the feed temperature, feed concentration, flow rate, operating time on the permeate flux were studied for treated and non treated membrane. In this work treated and non treated membrane were compared in terms of water flux, Within the tested range, MD with surface modified membrane the water flux has been significantly improved by treating the membrane surface.
\end{abstract}

\section{Nomenclature}

\begin{tabular}{|c|c|c|}
\hline \multicolumn{3}{|c|}{ Latin Symbols } \\
\hline$D$ & Diffusion coefficient & $\mathrm{m}^{2} / \mathrm{s}$ \\
\hline$r$ & Pore size & M \\
\hline$\Delta H_{\mathrm{c}}$ & Latent heat of condensation & $\mathrm{J} / \mathrm{kg}$ \\
\hline$\Delta H_{\text {vap }}$ & Latent heat of vaporization & $\mathrm{J} / \mathrm{kg}$ \\
\hline$h$ & Heat transfer coefficient & $\mathrm{W} / \mathrm{m}^{2} \mathrm{~K}$ \\
\hline J & Flux Mass flux & $\mathrm{kg} / \mathrm{m}^{2} \mathrm{~s}$ \\
\hline $\mathrm{N}$ & Molar flux & $\mathrm{kmol} / \mathrm{m}^{2} \mathrm{~s}$ \\
\hline k & Thermal conductivity & $\mathrm{W} / \mathrm{mK}$ \\
\hline LEP & Liquid entry pressure & $\mathrm{Pa}$ \\
\hline M & Molecular weight & Dalton \\
\hline$P$ & Pressure & $\mathrm{Pa}$ \\
\hline$Q$ & Heat transfer rate & W \\
\hline Q" & Heat flux & $\mathrm{W} / \mathrm{m}^{2}$ \\
\hline$R$ & Universal gas constant & $\mathrm{J} / \mathrm{mol} \mathrm{K}$ \\
\hline$T$ & Temperature & $\mathrm{K}$ \\
\hline TPC & Temperature polarization coefficient & - \\
\hline$t$ & Time & s \\
\hline$U$ & Overall heat transfer coefficient & $\mathrm{W} / \mathrm{m}^{2} \mathrm{~K}$ \\
\hline$u$ & Cross-flow velocity & $\mathrm{m} / \mathrm{s}$ \\
\hline V & Volume & $\mathrm{m}^{3}$ \\
\hline$w$ & Weight fraction & - \\
\hline$x, y$ & Molar fraction & - \\
\hline \multicolumn{3}{|c|}{ Greek Symbols } \\
\hline$\Delta$ & Difference & - \\
\hline$\delta$ & Membrane thickness & $\mu \mathrm{m}$ \\
\hline$\varepsilon$ & Membrane porosity & - \\
\hline$\mu$ & Liquid viscosity & Pas \\
\hline$\rho$ & Density & $\mathrm{kg} / \mathrm{m}^{3}$ \\
\hline$x$ & Tortuosity & - \\
\hline
\end{tabular}

Subscripts: av: Average; b: Bulk; f: Feed; i,j: Index; 1: Liquid; 1,2: Membrane; p: Permeate; v: Vapour; w: Water

Keywords: Membrane Distillation; Surface Modification; Orange Juice; Polytetrafluoroethylene

\section{Introduction}

Membrane distillation (MD) is a membrane technique that involves transport of water vapor through the pores of hydrophobic membranes due to a vapor pressure driving force provided by temperature and/ or solute concentration differences across the membrane. A variety of methods may be employed to impose this vapor pressure difference. [1-7]. In the present work, the direct contact membrane distillation method is considered. In this configuration the surfaces of the membrane are in direct contact with two liquid phases, the feed (warm solution) and permeate (cold solution), kept at different temperatures. A liquid vapor interface exists at the pore entrances where liquidvapor equilibrium is established. Inside the pores only a gaseous phase is present through which vapor is transported as long as a partial pressure difference is maintained. The vaporization takes place at the feed membrane interface. The vapor diffuses through the membrane pores and condenses at the permeate membrane interface. Thus, MD relies on vapor-liquid equilibrium as a basis for separation and requires that the latent heat of vaporization be supplied to achieve the characteristic phase change. Membrane distillation offers advantages like techniques suitable for heat-sensitive products, modularity, easy scale-up, possibility to treat solutions with high level of suspended solids, Possibility of using modules in series, low temperatures, low operating pressures, no fouling problems, constant permeate flux in time, new technologies based on the use of conventional well-tested materials and low investment cost. Drawbacks of the process can be compensating by enhancing the flux rate. This technology work with certain disadvantages like low evaporative capacity with a long time of treatment, necessity of an inactivation enzyme pre-treatment and low flux rate. The goal of the present article is to enhance flux rate by surface modification of membrane surface to make process more efficient and commercially viable.

*Corresponding author: Deshmukh S.K, Sant Gadge Baba Amravati University, Amravati, Maharashtra, India, E-mail: samirdesh23@yahoo.com

Received February 09, 2010; Accepted May 09, 2011; Published May 09, 2011

Citation: Deshmukh SK, Sapkal VS, Sapkal RS (2011) Performance Enhancement of Membrane Distillaiton Process of Fruit Juice. J Membra Sci Technol 1:104. doi:10.4172/2155-9589.1000104

Copyright: () 2011 Deshmukh SK, et al. This is an open-access article distributed under the terms of the Creative Commons Attribution License, which permits unrestricted use, distribution, and reproduction in any medium, provided the original author and source are credited. 
Direct Contact Membrane Distillation (DCMD) is not a simple process of mass transfer through the membrane, but a complex process combination of several interrelated heat and mass transfer steps. In fact, as vaporization takes place at the feed membrane interface and condensation at the permeate membrane interface, membrane distillation requires the heat of vaporization to be supplied to the feed vapor-liquid interface, and the heat of condensation to be removed from the vapor-liquid interface in the permeate side. Conductive heat transport through the thin membrane also takes place. As a consequence, thermal boundary layers develop at both sides of the membrane, that is, temperature polarization arises. On the other hand, concentration boundary layers develop in the liquid phases (that is, concentration polarization arises) if there is solute rejection by the membrane [7].

Orange juice is probably the best known and most widespread fruit juice all over the world, particularly appreciated for its fresh flavour and considered of high beneficial value for its high content in vitamin $\mathrm{C}$ and natural antioxidants, such as flavonoids and phenylpropanoids. The advantages of the concentration of the liquid foodstuffs include the reduction in packaging, storage, transport cost and prevention of deterioration by microorganisms. For these reasons, many concentration techniques have been developed and used for the food industries. They include evaporative concentration, freeze concentration, and membrane processes such as reverse osmosis (RO) and ultrafiltration (UF) [9-10].

Nevertheless, when concentration is carried out by traditional multi step vacuum evaporation, a severe loss of the volatile organic flavour/fragrance components occurs as well as a partial degradation of ascorbic acid and natural antioxidants, accompanied by a certain discolouration and a consequent qualitative decline. These effects are mainly attributable to heat transfer to the juice during evaporation. In order to overcome some of these problems and to better preserve the properties of the fresh fruits, several new "mild" technological processes have been proposed in the last years for juice production [8]. MD has many significant advantages, such as high system compactness, possibility to operate at low temperatures $\left(30-90^{\circ} \mathrm{C}\right)$ which makes it amenable for use with low temperature heat sources, including waste or solar heat, and, when compared with say reverse osmosis or electrodialysis, the simplicity of the membrane which allows it to be manufactured from a wide choice of chemically and thermally resistant materials, and much larger pores than of reverse osmosis membranes (and typically larger than in ultra-filtration membranes, that aren't nearly as sensitive to fouling [1-12].

\section{Material and Methodology}

\section{Module development}

Cross flow module of hydrophobic Polytetrafluoroethylene (PTFE) $0.2 \mu \mathrm{m}$ has been developed with the help of viton gasket, polyester mesh and adhesive. Module has length $11.5 \mathrm{~cm}$, breadth $10 \mathrm{~cm}$ and hydraulic diameter $2.28 \mathrm{~mm}$ is supported with stainless steel holding device. Module has effective membrane area $0.0115 \mathrm{~m}^{2}$.

\begin{tabular}{|l|l|}
\hline \multicolumn{2}{|c|}{ Module } \\
\hline Configuration & Flat Plate \\
\hline Membrane area, $\mathrm{m}^{2}$ & 0.0115 \\
\hline Material & PTFE \\
\hline Membrane thickness, & $160 \mu \mathrm{m}$ \\
\hline Nominal pore diameter, & $0.05-0.2 \mu \mathrm{m}$ \\
\hline Porosity (\%) & 70 \\
\hline
\end{tabular}

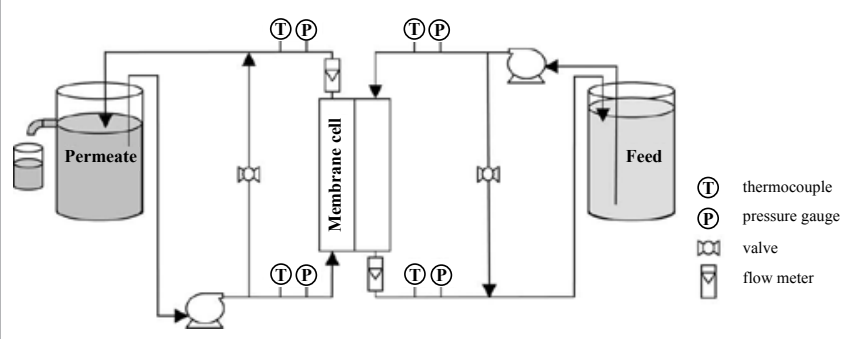

Figure 1: Flow Diagram of Membrane Distillation.

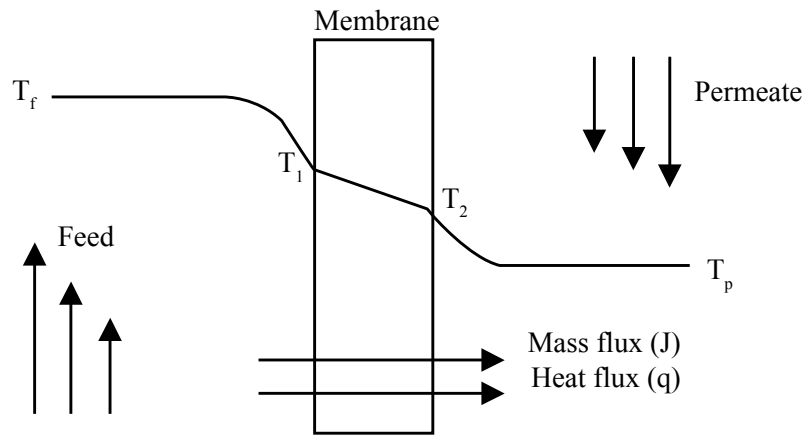

Figure 2: Heat and Mass Transfer in DCMD

\section{Treatment of PTFE membrane}

Surface modification of PTFE membrane has been carried out by treating membrane with $20 \%$ ethyl alcohol - water mixture for half an hour, which make it hydrophilic and then hydrophobicity was regained by drying.

\section{Sucrose solution}

The orange juice model solution used in this study was prepared with sucrose pro-analysis grade, citral (cis and trans mixture, 95\%) and ethyl butyrate, $98 \%$ (Aldrich, Germany) with initial concentration $11.5^{\circ}$ Brix.

\section{Experimental set up}

Concentration of sucrose solution by Direct contact membrane distillation was carried out using a flat-sheet membrane cell with an effective membrane area $0.0115 \mathrm{~m}^{2}$. The membrane cell was made of stainless steel and was placed in a vertical configuration. The system to be studied consists of a porous hydrophobic membrane, which is held between two symmetric channels. Hot feed is circulated through one of the channels and cold permeate through the other one. The hot and cold fluids counter-flow tangentially to the membrane surface in a flat membrane module. In our experiments, the membrane is sandwiched between two equal stainless steel manifolds. Microporous hydrophobic PTFE membrane of $0.2 \mu \mathrm{m}$ pore size and thickness $160 \mu \mathrm{m}$ was placed between polyester mesh $(0.28 \mathrm{~mm})$, polyviton gasket $(3 \mathrm{~mm})$ on both side which create the two identical flow channels, the membrane and the manifolds create spacer-filled flow channels for hot feed and cold permeate liquids.

Feed tank with thermostat, peristaltic pump, temperature and flow indicator is arranged in feed side, where as peristaltic pump, temperature and flow indicator is arranged in permeate side. Module is supported with stainless steel holding device. The schematic arrangement is 
shown in Figure 1.Sucrose solution as a model orange juice as feed solution and distilled water as receiving phase were contained in two jacketed reservoirs and were circulated through the membrane cell by one two-channel peristaltic pump. The feed and distillate streams flow counter currently from the bottom to the upper part of the membrane cell. Different experiments were carried out for fixed temperatures in the membrane module. The average feed temperature $\mathrm{T}_{\mathrm{f}}$ varied for the different experiments from 40 to $70^{\circ} \mathrm{C}$ and permeates temperature $\mathrm{T}_{\mathrm{p}}$ varied for the different experiments from 20 to $30^{\circ} \mathrm{C}$.

The linear velocity feed and permeate was also varied. Different experiments were carried out applying different recirculation rates. A drainage tube in the upper part of the receiving reservoir confined the total volume of receiving phase to about $100 \mathrm{ml}$. Excessive liquid due to permeate transferred across the membrane escaped from receiving reservoir and was collected in a graduated cylinder. The permeate volume was measured continuously as a function of time and these data were used for calculation of the permeate flux.

\section{Theory}

\section{Mass transfer}

Modeling of mass (vapor) transfer within the membrane pores has received most interest from Membrane Distillation investigators. Several Membrane Distillation model are available in literature each consider one or more of the following mass transfer mechanism across the membrane: viscous flow, Knudsen and molecular diffusion. If we have a porous media or a porous membrane filled by a gas mixture and a pressure gradient exists through the membrane, a form for the flux relations can be obtained, modeling the porous medium as a bundle of cylindrical capillaries and using momentum transfer considerations. The flux relations are, of course, founded on transport laws for a single capillary. According to mentioned transfer considerations, encounters between molecules or between a molecule and the capillary walls are accompanied by momentum transfer. As a result, there are three mechanisms, by which a given species of a gas mixture may lose momentum in the motion direction through a capillary,

(a) by a direct transfer to the capillary walls as a result of molecule-wall collisions (Knudsen resistance);

(b) by transfer to another species as a consequence of collisions between pairs of unlike molecules molecular resistance);

(c) by indirect transfer to the capillary walls via a sequence of moleculemolecule collisions terminating in a molecule-wall collision (viscous resistance).

Any theoretical study of gas permeation through microporous structures begins with a comparison of the mean free path of the gas and the mean pore size of the structure. If the mean free path of the gas is much less than the pore size, then the dominant flux mechanism is viscous or Poiseuille flow. If the mean free path is much greater than the pore size, then Knudsen diffusion is the dominant mechanism.

Knudsen number, which is the ratio of mean free path and pore diameter, dictate the type of mass transfer mechanism. If Knudsen number is less than 0.01 , the mass transfer mechanism is considered as molecular diffusion and $\mathrm{Kn}$ values higher thar 10, the mechanism is considered as Knudsen diffusion. If the values of $\mathrm{Kn}$ lies between $0.01-10$, it is the transition zone and both the mechanism contribute to the mass transfer.

$$
\mathrm{Kn}=\frac{\lambda}{2 r}
$$

$\mathrm{Kn}$ is Knudsen number and $\lambda$ is mean free path.

Mean free path is given by equation:

$$
\lambda=\frac{3.2 \mu_{v}}{P} \sqrt{\frac{R T}{2 \Pi M}}
$$

Where $\mu_{\mathrm{v}}$ is viscosity of vapors at atmospheric temperature and ambient pressure.

If the ratio $\mathrm{d} / \lambda$ (pore diameter to mean free path of the gas molecule $\lambda$ ) is greater than 20 , molecular diffusion is predominant, the molar flux is given by:

$$
\mathrm{N}_{\mathrm{A}}=\frac{N_{A}}{N_{A}+N_{B}}\left(\frac{D_{\text {eff }} P_{t}}{R T \chi}\right) \ln \left(\frac{\frac{N_{A}}{N_{A}+N_{B}}-y_{A 2}}{\frac{N A}{N A+N B}-y_{A 1}}\right)
$$

Where, $\mathrm{D}_{\text {eff }}=\mathrm{D}_{\mathrm{AB}} \frac{\varepsilon}{\chi}$

If the ratio $d / \lambda<0.2$ the rate of diffusion is governed by the collision of the gas molecules within the pore walls and follow Knudsen law, the mass flux is given by:

$$
\mathrm{J}=\frac{D_{K}\left[P_{A 1}-P_{A 2}\right]}{R T \chi},
$$

Where, $\mathrm{D}_{\mathrm{K}}=\left(\frac{d}{3}\right)\left(\frac{8 g_{c} R T}{\Pi M}\right)^{1 / 2}$

If $0.2<\mathrm{d} / \lambda<20$, both molecular and Knudsen diffusion takes place.

$$
\mathrm{N}_{\mathrm{A}}=\frac{N_{A}}{N_{A}+N_{B}}\left(\frac{D_{\text {eff }} P_{t}}{R T \chi}\right) \ln \left(\frac{\frac{N_{A}}{N_{A}+N_{B}}\left(1+\frac{D_{\text {eff }}}{D_{\text {Keff }}}\right)-y_{A 2}}{\frac{N A}{N A+N B}\left(1+\frac{D_{\text {eff }}}{D_{\text {Keff }}}\right)-y_{A 1}}\right)
$$

Rate of mass transfer in membrane distillation for laminar flow, recognizing that the transport regime would be in the Knudsen and Poiseuille transition is given by:

$$
\begin{aligned}
& \mathrm{J}=\frac{\varepsilon M D_{K P}}{\chi R T} \operatorname{In} \frac{P-P_{i P}}{P-P_{i f}} \\
& \mathrm{D}_{\mathrm{KP}}=\left(\frac{1}{D_{K}}+\frac{1}{D_{p}}\right)^{-1}
\end{aligned}
$$

For typical membrane distillation with pore size of $0.1-0.5 \mu \mathrm{m}$ diameter the flow could be influenced by both Knudsen and Poiseuille flow.

Recognizing that the transport regime would be in the Knudsen and Poiseuille transition.

$$
\mathrm{J}=\mathrm{a} \mathrm{P}^{\mathrm{b}} \Delta \mathrm{P}
$$

Where b can range from 0 (fully Knudsen) to 1.0 (fully Poiseuille). The parameter $\mathrm{a}$ and $\mathrm{b}$ vary with molecular weight and membrane type.

The transport of water vapor many be impeded if air is trapped in the pores. This is quite probable if the feed is not deairated. For steady state diffusion through a stationary air-film we can write:

$$
\begin{aligned}
& \mathrm{J}=\frac{1}{\left(P_{a}\right) \operatorname{Im}} \frac{\varepsilon}{\chi \delta} \frac{D P M}{R T} \Delta P \\
& \mathrm{~J}=\frac{d}{\left(P_{a}\right)} \Delta P
\end{aligned}
$$

The combine effects of the Knudsen and Poiseuille flow and hindered diffusion can be written 


\section{Flux Vs Feed Flow Rate}

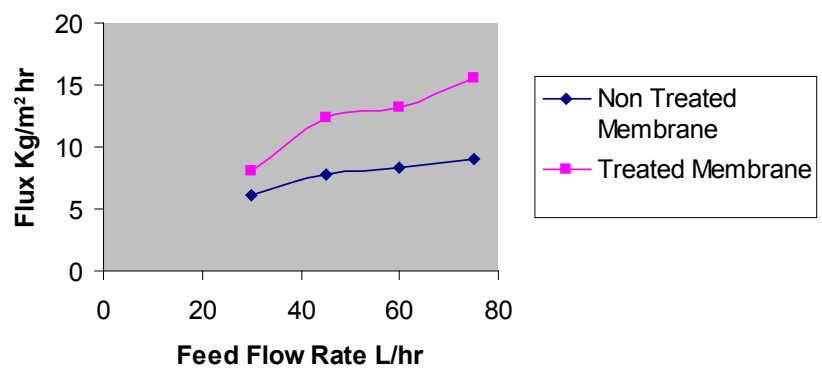

Figure 3: Effect of feed velocity on transmembrane flux using PTFE membrane (Permeate flow rate $60 \mathrm{~L} / \mathrm{hr}$, Feed temperature $50^{\circ} \mathrm{C}$, permeate temperature $30^{\circ} \mathrm{C}$ and $11.5^{\circ}$ Brix)

\section{Flux Vs Brix}

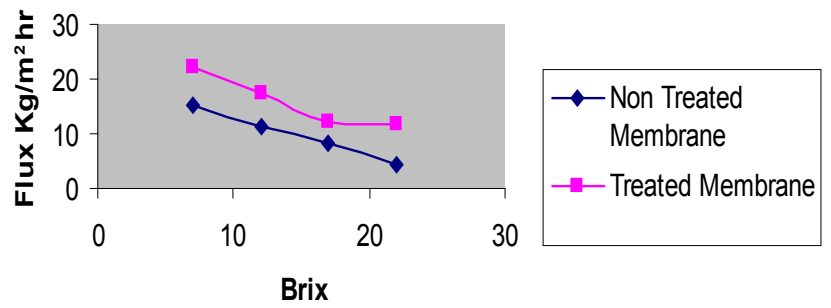

Figure 4: Effect of concentration on flux using PTFE membrane (Feed flow rate $72 \mathrm{~L} / \mathrm{hr}$, Permeate flow rate $30 \mathrm{~L} / \mathrm{hr}$, Feed temperature $50^{\circ} \mathrm{C}$, permeate temperature $30^{\circ} \mathrm{C}$ )

$$
\mathrm{J}=\left[\frac{1}{a P^{b}}+\frac{P_{a}}{d}\right]^{-1} \Delta P
$$

In the system studied the vapor transport through the membrane pores takes place via combined Knudsen/molecular and Poiseuille flow mechanism. In this case $C$ may be written:

$$
\mathrm{C}=\left[\frac{1}{D_{K}}+\frac{1}{D_{m}}+\frac{1}{D_{P}}\right]
$$

The form of the proposed Knudsen, molecular and Poiseuille flow transition (KMPT) mode is:

$$
\mathrm{J}=\left[\frac{1}{\frac{1}{C_{K}}\left(\frac{1}{R T_{m}}\right)^{0.5}+\frac{1}{C_{m}}\left(\frac{D M}{y_{I n} R T_{m}}\right)}+C_{p}\left(\frac{M P_{m}}{\mu R T_{m}}\right)\right]\left(\mathrm{P}_{1}-\mathrm{P}_{2}\right)
$$

Where, $\mathrm{C}_{\mathrm{K}}=\frac{r \varepsilon}{\chi \delta}, \mathrm{C}_{\mathrm{m}}=\frac{\varepsilon}{\chi \delta}$ and $\mathrm{C}_{\mathrm{p}}=\frac{r^{2} \varepsilon}{\chi \delta}$

\section{Heat transfer}

The heat transfer equations governing heat flows in and around the membrane are:

Neglecting the heat flux that occurs due to concentration gradient and the possible radiative heat flux, the total heat flux from the feed bulk to the membrane can be written as:

$$
\mathrm{Q}_{\mathrm{f}}{ }^{\prime}=\mathrm{h}_{\mathrm{f}}\left(\mathrm{T}_{\mathrm{f}}-\mathrm{T}_{1}\right)
$$

The heat transfer inside the membrane is divided into two possible mechanisms, conduction across the membrane material together with the heat flowing through the membrane. With the assumption of nonlinear temperature distribution and non-isenthalpic flow, the heat transfer equation inside the membrane is given by:

$$
\begin{aligned}
& \mathrm{Q}_{\mathrm{m}}{ }^{\prime}=\mathrm{Qv}^{\prime}+\mathrm{Q}_{\mathrm{c}}{ }^{\prime} \\
& =\mathrm{J} \Delta \mathrm{H}_{\mathrm{v}}+\left(\mathrm{k}_{\mathrm{m}} / \delta\right)\left(\mathrm{T}_{1}-\mathrm{T}_{2}\right)
\end{aligned}
$$

Where, $\Delta \mathrm{H}_{\mathrm{v}}$ is the vapor enthalpy at temperature $\mathrm{T}$ and $\mathrm{k}_{\mathrm{m}}$ is the thermal conductivity coefficient which can be determine on the basis of membrane material data:

$$
\mathrm{Q}_{\mathrm{c}}{ }^{\prime}=\left(\mathrm{k}_{\mathrm{m}} / \delta\right)\left(\mathrm{T}_{1}-\mathrm{T}_{2}\right)=\mathrm{h}_{\mathrm{m}}\left(\mathrm{T}_{1}-\mathrm{T}_{2}\right)
$$

$\mathrm{k}_{\mathrm{m}}$ is thermal conductivity of the membrane that is contributed from both polymer material $\left(\mathrm{k}_{\mathrm{s}}\right)$ and gases $\left(\mathrm{k}_{\mathrm{g}}\right)$ which are usually air and water vapor. In this case of air-water vapor mixture, there is small difference between their thermal conductivities.

$$
\begin{aligned}
& \mathrm{h}_{\mathrm{m}}=\left(\varepsilon \mathrm{K}_{\mathrm{g}}+(1-\varepsilon) \mathrm{K}_{\mathrm{s}}\right) / \delta \\
& \mathrm{Q}_{\mathrm{v}}{ }^{\prime}=\mathrm{J} \Delta \mathrm{H}_{\mathrm{v}}=\mathrm{h}_{\mathrm{v}} \Delta \mathrm{T}_{\mathrm{m}}=\mathrm{hv}\left(\mathrm{T}_{1}-\mathrm{T}_{2}\right) \\
& \mathrm{H}_{\mathrm{v}}(\mathrm{T})=\mathrm{H}_{\mathrm{v}}\left(\mathrm{T}_{\mathrm{o}}\right)+\mathrm{Cp}_{\mathrm{v}}\left(\mathrm{T}-\mathrm{T}_{\mathrm{o}}\right)
\end{aligned}
$$

Where $\mathrm{H}_{\mathrm{v}}\left(\mathrm{T}_{\mathrm{o}}\right)$ is the heat of vaporization at reference temperature $\mathrm{T}_{\mathrm{o}}$ and $\mathrm{Cp}_{\mathrm{v}}$ is specific heat of vapor. Generally, the reference temperature $\left(\mathrm{T}_{0}\right)$ is $273 \mathrm{~K}$. With the vapor-liquid equilibrium assumption, the thermodynamic properties can be applied. For water vapor, $\mathrm{Cp}_{\mathrm{v}}$ $=1.7535 \mathrm{KJ} / \mathrm{Kg} \mathrm{K}$ for the range of temperature $0-100^{\circ} \mathrm{C}$ and $(\mathrm{Hv} \mathrm{x}$ $273.15)-\left(\mathrm{Cp}_{\mathrm{v}} \times 273.15\right)=2024.3 \mathrm{KJ} / \mathrm{Kg}$.

Then equation 21 can be written as:

$$
\mathrm{H}_{\mathrm{v}}(\mathrm{T})=1,7535(\mathrm{~T})+2024.3
$$

The total heat flux from the membrane to the bulk permeates can be written as:

$$
\mathrm{Q}_{\mathrm{p}}{ }^{\prime}=\mathrm{hp}\left(\mathrm{T}_{2}-\mathrm{T}_{\mathrm{p}}\right)
$$

The film heat transfer coefficients can be estimated from appropriate correlations or may be determined experimentally.

\section{Result and Discussion}

The effect of various process parameters such as feed flow rate, temperature difference and concentration are discussed in the following section.

\section{Effect of feed velocity}

Effect of feed flow rate on transmembrane flux for sugar solution is estimated for both treated and nontreated membrane and presented in Figure 3. During experiments, the feed side flow rate is varied and permeate side flow rate $(30 \mathrm{~L} / \mathrm{hr})$, temperature difference $(\Delta \mathrm{T}=$ $\left.20^{\circ} \mathrm{C}\right)$, and concentration was maintained constant $\left(11.5^{\circ} \mathrm{Bx}\right)$. The transmembrane flux in both case increases with increase in flow rate. The increase is mainly due to the reduction in temperature and concentration polarization. The higher the cross flow rate appeared to improve flux indicating that the increasing shear rate on temperature and concentration polarization was evident. The increase in case of treated membrane resulted in $36-43 \%$ increase in flux.

\section{Effect of feed concentration}

The concentration of sucrose solution was varied over $7-22^{\circ}$ Brix. During the experiments the feed flow rate, permeate flow rate and temperature difference are maintained constant. The values of transmembrane flux observed at different concentration of feed 


\section{Flux Vs Teperature Difference}

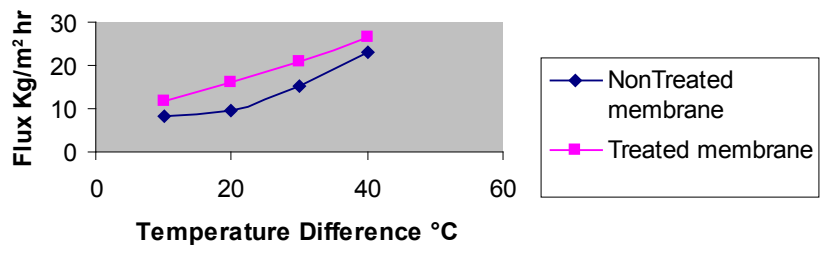

Figure 5: Effect of $\Delta \mathrm{T}$ on transmembrane flux using PTFE membrane (Feed flow rate $72 \mathrm{~L} / \mathrm{hr}$, Permeate flow rate $30 \mathrm{~L} / \mathrm{hr}$, permeate temperature $30^{\circ} \mathrm{C}$ and $11.5^{\circ}$ Brix).

\section{Flux Decline Characteristic of Treated Membrane}

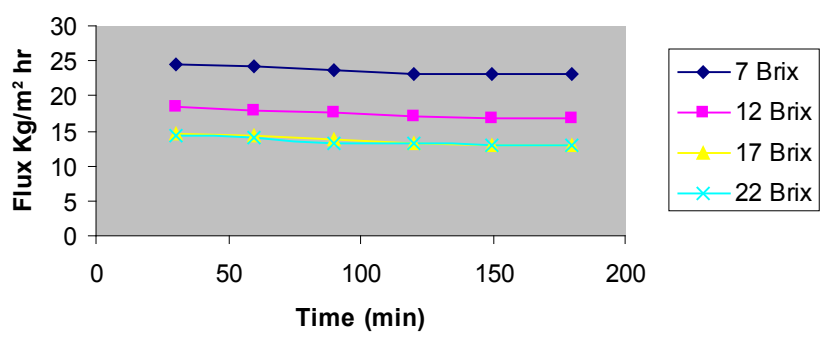

Figure 6: Flux declining rate.

solution are shown in Figure 4 The transmembrane flux for both treated and nontreated decreases with increase in concentration.

\section{Effect of temperature difference}

Figure 5 show the results obtained at four constant temperatures of juice in the hot cell $\left(40^{\circ} \mathrm{C}, 50^{\circ} \mathrm{C}, 60^{\circ} \mathrm{C}\right.$ and $\left.70^{\circ} \mathrm{C}\right)$ with constant cold cell temperatures. During experiments the feed and permeate velocity were maintained constant. The flux was calculated based on experimental data using the following equation:

$$
\mathrm{J}=\frac{\text { measured permeate flow rate }}{\text { membrane area }}
$$

The fluxes exhibit an exponential dependence on temperature-as would be expected when considering the Antoine equation for vapor pressure of water:

$$
\mathrm{p}_{\text {mi }=\exp }\left(23.238-\frac{3841}{T m i-45}\right), \mathrm{i}=1,2
$$

where $p$ is the vapor pressure of water in $\mathrm{Pa}$ and $T$ is the temperature in $\mathrm{K}$.

This is due to the exponential increase of the vapor pressure of the feed solution with temperature, which increases the transmembrane vapor pressure (i.e. the driving force) as all the other involved MD parameters are maintained invariables. It was stated that it is better to work under high feed temperature as the internal evaporation efficiency, defined as the ratio of the heat that contributes to evaporation and the total heat exchanged from the feed to the permeate side is high although the temperature polarization effect increases with the feed temperature.

\section{Flux decline characteristics of treated membrane}

In addition to above experiments, another experiment was performed to study flux decline rate with respect to time. With feed at flow rate $72 \mathrm{~L} / \mathrm{hr}$, permeate flow rate $30 \mathrm{~L} / \mathrm{hr}$, Temperature difference $20^{\circ} \mathrm{C}$, feed temperature $50^{\circ} \mathrm{C}$ and permeate temperature $20^{\circ} \mathrm{C}$, with constant water addition thus maintaining a uniform concentration throughout the run. The aim of these experiments was to study the flux decay in membrane distillation for treated membrane. The result indicates that it was possible to consistently remove water at steady value of approximately $20-25 \mathrm{Kg} / \mathrm{m}^{2} \mathrm{hr}$.

\section{Conclusion}

The concentration of sucrose solution as a model orange juice was carried out by direct contact membrane distillation for both treated and non treated PTFE membrane. The influence of various parameters such as feed flow rate, temperature difference, and concentration of sugar solution with respect to transmembrane flux were studied for real system. It was observed that transmembrane flux for treated membrane was $36-43 \%$ more than nontreated membrane. The experiments were performed to study the flux decay in membrane distillation for treated membrane for different viscosity.

\section{Acknowledgement}

The authors are indebted to University Grant Commission, New Delhi for financial support for this wok.

\section{References}

1. Lawson KW, Lloyd DR (1997) Review on Membrane distillation. Journal of membrane Science 124: 1-25.

2. Mengual JI, Pena L (1997) Membrane distillation Colloid Interf. Sci 1: 17-29.

3. Schofield RW, Fane AG, Fell CJD (1987) Heat and mass transfer in membrane distillation. Journal of membrane Science 33: 299-313.

4. Khayet M, Godino Paz, Mengual JI (2000) Theory and experiments on sweeping gas membrane distillation. Journal of membrane Science 165: 261-272.

5. Banat FA, Simandl J (1994) Theoretical and experimental study in membrane distillation. Desalination 95: 39-52.

6. Bandini S, Gostoli C, Sarti GC (1992) Separation efficiency in vacuum membrane distillation. Journal of membrane Science 73: 217-229.

7. Martınez L, Rodrıguez-Maroto JM (2007) On transport resistances in direct contact membrane distillation. Journal of Membrane Science 295: 28-39.

8. Galaverna G, Silvestro GD, Cassano A, Sforza S, Dossena A, et al (2007) A new integrated membrane process for the production of concentrated blood orange juice. Effect on bioactive compounds and antioxidant activity. Food chemistry 106: 1021-1030.

9. Thanedgunbaworn R, Jiraratananon R, Nguyen MH (2007) Mass and hea transfer analysis in fructose concentration by osmotic distillation process using hollow fibre module. Journal of Food Engineering 78: 126-135.

10. Bagger-Jorgensen R, Meyer AS, Varming C, Jonsson G (2004) Recovery of volatile aroma compounds from black currant juice by vacuum membrane distillation. Journal of Food Engineering 64: 23-31.

11. Alklaibi AM, Lior N (2005) Transport analysis of air-gap membrane distillation Journal of Membrane Science 225: 239-253.

12. Ali F, Dornier M, Duquenoy A, Reynes M (2003) Evaluating transfers of aroma compounds during the concentration of sucrose solutions by osmotic distillation in a batch-type pilot plant. Journal of Food Engineering 60: 1-8.

13. Ravindra Babu B, Rastogi NK, Raghavarao KSMS (2005) Mass transfer in osmotic membrane distillation of phycocyanin colorant and sweet-lime juice. Journal of Membrane Science

14. Nene S, Kaur S, Sumod K, Joshi B, Raghavarao KSMS (2002) Membrane distillation for the concentration of raw cane-sugar syrup and membrane clarified sugarcane juice. Desalination 147: 157-160.

15. Patil G, Raghavarao KSMS (2007) Integrated membrane process for the concentration of anthocyanin. Journal of Food Engineering 78: 1233-1239. 
Citation: Deshmukh SK, Sapkal VS, Sapkal RS (2011) Performance Enhancement of Membrane Distillaiton Process of Fruit Juice. J Membra Sci Technol 1:104. doi:10.4172/2155-9589.1000104

16. Bailey AFG, Barbe AM, Hogan PA, Johnson RA, Sheng J (2000) The effect of ultrafiltration on the subsequent concentration of grape juice by osmotic distillation. Journal of Membrane Science164: 195-204.

17. Oleksandr Lukanin S, Sergiy Gunko M, Mikhaylo Bryk T, Rinat Nigmatullin R (2003) The effect of content of apple juice biopolymers on the concentration by membrane distillation. Journal of Food Engineering 78: 275-280.

18. Barbe AM, Hogan PA, Johnson RA (2000) Surface morphology changes during initial usage of hydrophobic, microporous polypropylene membranes. Journal of Membrane Science 172: 149-156.

19. Martinez $L$ (2004) Comparison of membrane distillation performance using different feeds. Desalination 168: 359-365.

20. Hanbury WT, Hodgkiess T (1985) Membrane Distillation. An Assessment Desalination 56: 287-297.

21. Jonsson AS, Wimmerstedt R, Harrysson AC (1985) Membrane Distillation - A theoretical study of evaporation through microporous membrane. Desalination 56: $237-249$.

22. Drioli E, Yonglie Wu (1985) Membrane Distillation - An Experimental Study, Desalination 56: 339-346.
23. Tomaszewska M (2000) Membrane Distillation-Examples of Applications in Technology and Environmental Protection. Polish Journal of Environmental Studies 9: 27-36.

24. El-Bourawi MS, Ding Z, Ma R, Khayet M (2006) A framework for better understanding membrane distillation separation process. Journal of Membrane Science 285: 4-29

25. Jiao BL, CalbroV, Drioli E (1992) Concentration of Orange and Kiwi Juice by integrated Ultrafiltration and Membrane Distillation. Paper presented at 'IMSTEC' 92 held at Sydney Australia, 10-12 November 1992, 7-8.

26. Cerneaux S, Struzynsk I, Kujawski WM, Persin M, et al. (2009) Comparison of various membrane distillation methods for desalination using hydrophobic ceramic membranes. Journal of Membrane Science 337: 55-60.

27. Alves VD, Coelhoso IM (2006) Orange juice concentration by osmotic evaporation and membrane distillation. A comparative study. Journal of Food Engineering 74: 125-133.

28. Cassano A, Jiao B, Drioli E (2004) Production of concentrated kiwifruit juice by integrated membrane process. Food Research International 37: 139-148. 